\title{
Transparency and Social Accountability in School Management
}

\author{
Raffaella Cassano*
}

\begin{abstract}
The EU strategy of intelligent, sustainable and inclusive growth and the spending review ask for effective and transparent models of performance improvement of the public institutions. The importance of good governance is particularly evident against fundamental and inalienable individual rights like instruction and training. Recent reforms of Italian educational system impose rapid changes in the school governance system, high demand for managerial skill and operational autonomy, the capability to optimize performance, dialogue with stakeholders, and transparency of behaviour. The Italian school is called to face a profound change to improve its performance and to build an effective network with its stakeholders.
\end{abstract}

Keywords: Transparency; Accountability; School Governance; Sustainability; Network Governance; Global Markets

\section{The Change in School Governance}

In most European countries, recent regulatory reforms introduced new models, processes and opportunities to improve the quality of the education system and the autonomy of the schools, mainly linked to the following aspects:

- Improvement of the perceived responsibility about contents and methods.

- Identify the responsibilities of the school and responsible government bodies in respect of third parties.

- $\quad$ Reduced the constraint by the institutional protection provided by central or local administrative systems.

- Development of significant personal relations between relevant stakeholder and management skills needed for an effective and transparency governance.

Although the effectiveness of the school system has always been a central issue in the reform plans of all European countries, it is becoming more and more relevant according to objectives of intelligibility, transparency, sustainability and inclusive development supported by the International Agreements. Currently the investments in human capital are a decisive factor for the sustainability and the development of future conditions of the planet.

\footnotetext{
*Assistant Professor of Management, University of Brescia (raffaella.cassano@unibs.it)
} 
In September 2015 the UN Member States shared the adoption of Agenda 2030 for sustainable development. This is unique agreement, which will lead to a significant influence on socio-economic, political and environmental issues at global level in the next fifteen years. The unsustainable nature of the current model of development (on environmental plan, but also economic and social plan) has represented the main lever which was put to point this agreement. The agreement expresses a crossmultidimensional program, operating in all fields of economic life, of the social and environmental sphere. In this respect, the world educational is called actively to play its role toward an action of growth, inclusion and quality improvement with continuity. Specifically, Goal 4, structured in ten targets, aims to "Ensure inclusive and equitable quality education and promote lifelong learning opportunities for all" (UN, 2015).

The recent reform introduced in Italy fits in the perspective outlined above.

The DPR n. 80/2013 introduces in the Italian system law the National Evaluation System aimed to convey an idea of autonomy and responsibility of development and improvement able to permeate the entire organization of the school by increasing the positive impacts on the quality system of training and education. The essential steps of the school systems evaluation process includes:

1. Schools self-evaluation.

2. External evaluation.

3. Actions of improvement.

4. Social reporting of educational institutions.

In 2015, the Italian legislator intervened with another measure that strengthens the autonomous management of schools, requiring high managerial skills in school management with a view to transparency, assessment and improvement of the use of resources (Salvioni \& Cassano, 2017).

In other words, the regulatory changes and the evolution of the socio-politicaleconomic international and national highlight the need for profound change in school governance. The aim of the school's changing process is to provide a socially responsible governance system that satisfies the stakeholder expectations and is based on a plan do-check-act circular management model.

Increasing management autonomy and the advent of an integrated concept of responsibility, based on the effectiveness of stakeholder relations, involve a rethinking of school communication, in order to determine transparent and shared accepted management. The school must therefore provide a system of social accountability able to undertake an evaluation of the educational institution as a whole, in coherence with the new status of autonomy.

\section{Transparency and Autonomy in the School Management}

The autonomy of the school system is an essential condition which is connected to the introduction of appropriate governance structures headed by skilfull and competent leaders with a high educational culture and, at the same time, remarkable managerial skills.

The consolidation of the school autonomy and the national system of evaluation 
represent the condition to develop of stable and effective governance structures. This condition is essential to improve the efficiency of the integrated system of training for the entire cycle of education.

Already in 2012 the results of international scientific research carried out by the University of Brescia on "School Governance to build a learning community" stressed a great difficulty of management of individual schools for the lack of specific skills base.

In particular it is perceived the importance of the development of the educational process and of the evaluation systems to the activation of the process of learning and of constant improvement in the quality of the school system, but the necessary skills and tools are not ever available for its implementation (Franzoni \& Gennari, 2013; Salvioni, Gandini, Franzoni, Gennari, 2012).

In this context school management must focus on: the relation between schoolterritory to promote high quality of education in an inclusive vision and to offer equal opportunities; to grow the conditions for the alternation school-work oriented to lifelong learning and to increase the life experiences for the student; engagement of all stakeholders to the exploitation of the concept of global citizenship; ensure the right to study for all citizens and the best conditions for learning, growth and internationalization; the requalification of the built heritage devoted to education; the digital innovation of methods of teaching and learning (Boeve-De-Pauw, Gericke, Olsson, Berglund, 2015; Burton \& Dunn, 2005; Stubbs \& Cocklin, 2008). An effective and efficient school requires the dissemination of appropriate managerial skills to school leaders; the activation of suitable measuring systems, assessment and control; the implementation of consistent reporting systems able to ensure transparency in relations between the school and its stakeholders.

The reform of the Italian school system incorporates the need for development of processes of formation and evaluation mechanisms aimed at enabling learning paths and constant improvement of the quality of the school system by means of an integrated process of self-evaluation, external evaluation and social reporting.

The success of this reform connects however to the skills and tools needed for its implementation. Becomes crucial the development of the culture of the evaluation and of the transparency, which condition to improve the stakeholders relationship, the quality of the learning offered and optimal management of resources.

The transformation of the guidelines for sustainability in actual results entails the adoption of suitable tools and processes to guarantee the constant monitoring for effective implementation. The values of global responsibility configure, such evidence essential factors of integration between government bodies and organization (Salvioni \& Astori, 2013). Hence the need for provision of documents, actions and procedures to ensure the effective implementation (Salvioni, Astori, Cassano, 2014).

In a system of school governance based on the principles of autonomy and responsible management, it is essential the full knowledge of the principles and values shared by the top and by the organization (management, technical-administrative staff and teacher) as well as the definition of rules of conduct intended to ensure the quality of the decisions taken by the top and its correct development, so as to minimise the risks of dispersion and increasing skills (Hooijberg \& Lane, 2009; Uitto \& Saloranta, 2017). 
The National Evaluation System introduced by Presidential Decree n. 80/2013 is aimed at institutional accountability, the self-assessment of processes and actions to the programming of the improvement plans and the development of the organization in order to strengthen and make a real experience the school autonomy in a transparency vision. Transparency of governance policy relates to the vision, mission, purpose and main objectives of a school.

Transforming the strategy into actual results entails disseminating in all the behaviours of a sustainability culture and implementing appropriate systems of transparent accountability towards internal and external stakeholders (Mitchell, Van Buren, Greenwood, Freeman, 2015).

The institutionalization of the principle of sustainability is only achieved when accepted and integrated in the school governance culture and progressively becomes part of the activities implemented (Lozano, 2006; Tilbury, 2011). In other words, the governance approach of schools oriented to social responsibility is aimed at enhancing the close interdependence between economic and social efficiency, optimizing performance along the triple bottom line and involving all the management processes: from research and teaching to administrative and service activities, from the top management to the entire organization. This approach is implemented in both behaviors and internal communications, in external relationships and accountability (Gandini, Gennari, Cassano, 2014). A partial vision of the theme does not lead to real change and a holistic approach to sustainable development.

The inspiring logic of the national reform is in line with the goal n. 4 of Agenda 2030 that involves obtaining a quality education, fair and inclusive as learning opportunities for all, opening a matter for reflection on the important role that educational institutions at all levels of cover for the sustainable development of the planet. In particular, specific indicators of Goal 4 focus on actions and the school processes that lead to the full education for all individuals. An instruction basically of quality, fair, free from any discrimination or restriction. An ambitious goal that requires a total maturation process, on the one hand, culture toward logic of transparency, responsibility and sustainability; on the other hand, governance toward the principles of management autonomy and resource optimization and performance.

\section{Social Accountability in the School System}

The adoption of an integrated concept of responsibility focused on effective relations with stakeholder, emphasizes the importance of school communication. Actually, the compulsory school represents particular importance because it is a compulsory educational path for all citizens and its quality is essential for the education of future human capital.

The school autonomy enlarges the school responsibility area and makes the need of accountability significant (Salvioni \& Cassano, 2015). Therefore becomes relevant the choice of the best model of accountability able to determine the connection between autonomy and responsibility of the school. The effectiveness of reporting is primarily linked to the achievement of the objectives of:

To meet the needs of stakeholders to know the public value created and to 
express with transparency the school decisions.

- To realize the interinstitutional coordination on local development policies for a governance oriented to active citizenship.

- To create the reputational conditions to justify a greater and better participation of the stakeholders.

- To put to system the experiences of quality management and self-assessment of the institute, recognizing in the tools of accountability the conclusion of the cycle of school management.

Accountability is the result of an interaction between process and reporting tool aiming at informing the stakeholders and managing the relations with the latters underlining with transparency their responsibilities. In particular, the effective fulfilment of stakeholders' expectations is linked to the school ability to manage their responsibilities in an integrated manner and activate motivating engagement processes.

Therefore, the reporting process, intended as method, requires the consideration of ethical values and principles at the base of responsibility such as transparency, comparability, inclusiveness, accuracy, completeness, clarity, neutrality and effectiveness.

With this regard, it is pointed out that, for a considerable period, the traditional institutional communication of the schools has been insufficient and inefficient concerning transparency and information completeness. In the following table main traditional tools of accountability are summarized underlining the informative content, the recipients of the communication and the communication limits (Table 1).

Table 1: Communication Tools in Italian School System

\begin{tabular}{|c|c|c|c|}
\hline Tools & Informative content & Recipients & Informative limits \\
\hline $\begin{array}{l}\text { PTOF } \\
\text { (Italian } \\
\text { acronym for } \\
\text { Educational } \\
\quad \text { plan) }\end{array}$ & $\begin{array}{|lr|}\text { School } & \text { identity, } \\
\text { values, } & \text { mission, } \\
\text { strategies, didactic and } \\
\text { pedagogic } & \text { choice, } \\
\text { Organizational } & \text { Model, } \\
\text { annual training } & \text { project } \\
\end{array}$ & $\begin{array}{l}\text { Teachers } \\
\text { Students } \\
\text { Families } \\
\text { Management } \\
\text { bodies } \\
\text { audience }\end{array}$ & $\begin{array}{l}\text { It establishes objectives and programs } \\
\text { but does not inform about the obtained } \\
\text { results. It does not contain information } \\
\text { on economical and human resources. } \\
\text { It is strongly oriented to internal } \\
\text { representatives }\end{array}$ \\
\hline $\begin{array}{r}\text { Internal } \\
\text { regulation }\end{array}$ & $\begin{array}{l}\text { Rules of behaviours } \\
\text { of "internal population" }\end{array}$ & $\begin{array}{l}\text { rs, } \\
\text { staff }\end{array}$ & Ori \\
\hline $\begin{array}{r}\text { Ant } \\
\text { progi }\end{array}$ & $\begin{array}{l}\text { Income and expenses } \\
\text { classified for programs } \\
\text { and projects (according } \\
\text { to POF); functions/roles } \\
\text { and services }\end{array}$ & $\begin{array}{l}\text { Management } \\
\text { bodies } \\
\text { administration } \\
\text { board } \\
\text { bodies of } \\
\text { control }\end{array}$ & $\begin{array}{l}\text { Relevant in reference to general costs. } \\
\text { It is not suitable for analytical } \\
\text { accounting. } \\
\text { Almost entirely directed to internal } \\
\text { representatives }\end{array}$ \\
\hline $\begin{array}{c}\text { Report on } \\
\text { annual activity }\end{array}$ & $\begin{array}{l}\quad \text { Pursued objectives } \\
\text { and Balance resources } \\
\text { articulated in projects, } \\
\text { expected results, } \\
\text { guideline to read } \\
\text { quotation }\end{array}$ & $\begin{array}{l}\text { Management } \\
\text { bodies, control } \\
\text { bodies }\end{array}$ & $\begin{array}{l}\text { Rarely, expected results are } \\
\text { accompanied by performance indicators. } \\
\text { The link between resources and } \\
\text { project development is often } \\
\text { nominal/virtual, editing only the } \\
\text { indication of the PTOF }\end{array}$ \\
\hline
\end{tabular}




\begin{tabular}{|l|l|l|ll|} 
Final balance & $\begin{array}{l}\text { Incomes divided } \\
\text { according to their } \\
\text { nature, expenses } \\
\text { articulated in programs } \\
\text { and projects, functions } \\
\text { and services } \\
\text { financial } \\
\text { management results }\end{array}$ & $\begin{array}{c}\text { Management } \\
\text { bodies }\end{array}$ & $\begin{array}{c}\text { It is directed almost exclusively to } \\
\text { administration } \\
\text { board } \\
\text { control bodies }\end{array}$ & $\begin{array}{l}\text { Prevalence } \\
\text { information. } \\
\text { Indicators of effectiveness and } \\
\text { efficiency are absent }\end{array}$ \\
& & \\
\hline
\end{tabular}

Recognizing the importance of interaction with all major stakeholders emphasizes the need for improved communication and promotes the most adequate contents and ways of dissemination to meet stakeholders' needs of information and evaluation. The introduction of mechanisms of accountability, oriented to sustainability in schools, if properly structured and correctly managed, leads to improvements in: strengthening the link between statements of mission and adopted strategies; involvement of the social partners; appreciation of the results; point out the "added value" brought by the school.

The enlargement of information required for a more transparent governance is accompanied by new methods for content dissemination, linked to the increasingly appropriate tools to facilitate both the access to the information and the timeliness (Salvioni \& Bosetti, 2014). ICT development has made the communication more effective, thanks to the reduction of costs and time for preparing and disseminating information; moreover, ICT has knocked down space barriers, accelerating the fulfilment of information symmetry and the possibilities of constructive comparison.

\section{Impact of Social Accountability System in the Cycle of Performance School Management}

Educational institutions play a crucial role in the development of economic systems based on disseminating knowledge and innovation, promoting a more resourceefficient economy, greater environmental friendliness and competitiveness to foster cultural growth and social and territorial cohesion (Salvioni, Franzoni, Cassano, 2017). In this regard, in business economics' literature there are several models wellknown among which there are those that have had more success in the school system (Bradely, Crounchely, Millington, Taylor, 2000; Hastings \& Chapman, 2009; Brondoni, 2015; Kerr \& Dyson, 2016). In alternative to the "traditional bureaucratic model" there are the "Quasi-markets", "distributed governance" and "Network Governance" models with their relative accountability procedures (le Grand, 1991; Bradely, Crounchely; Millington, Taylor, 2000; West \& Pannel, 2002).

The Traditional bureaucratic model is the pyramidal setting of relations in the traditional ministerial structure required that the top managers' role (headmasters) was limited to defend education in the territory following the directions received from the central system and therefore exerting undisputed hegemony on teachers. Students and their families represented the last link of the chain with limited possibilities of expression or influence on school life.

The Quasi-markets model is based on the competition among numerous potential 
service suppliers to attract demand (Le Grand 2006). In other words, a Quasi-markets in education sector stimulates conditions of efficiency, effectiveness and equity towards: effective competition; availability of accurate and independent information on service characteristics; limited transaction costs; existence of financial motivations and elimination of "cream-skimming" practices. The versatility of the model permits its application in different fields, among which the educational school system (Exworthy, Powell, Mohan 1999; Mackintosh, 1992; Hastings \& Chapman 2009; Cassano \& Franzoni 2010; Aggarwal, 2000; Tooley \& Dixon, 2005).

Nevertheless, it is necessary to point out that the Italian school service is characterized by a limited freedom of families in choosing the school where to enroll their children, thus vanishing the model applicability.

The criterion of Quasi-markets, even reflecting some characteristics of the school system (presence of more categories of involved actors, discretion of choice, variety of suppliers), is not functional for the actuation of inspiration principles of the education reforms.

In the model of Distributed Governance, the school is directed to influence determinant decision areas which are excluded from its own direct control: policies for offer planning and territorial educational network; local policies for the right to study; territorial agreements for integration actions and promotion of the training success; infrastructures improvement; coordination and functionalities of school support services; allocation of human resources.

Undoubtedly, the model represents a significant management evolution directed to ensure the enhancement of relations of proximity during the determination of lines of the entire school system development, but significant references in terms of stakeholder engagement are absent. Therefore, conflicts of interests connected to power relations may arise.

The Network Governance model relationship management is the method of development of the aims of this paper. Network is intended as a non-hierarchic structure of interrelated elements, where information flows easily and rapidly. The network implies a huge cultural change at first and then an organizational one (Brondoni, 2014; Albareda \& Waddock, 2016; Cullen-Lester, Woehler, Willburn, 2016). It is a managerial approach, which fosters the enhancement of human resources, considered crucial in organizations, the empowerment and the stakeholders' equity of treatment.

The learning community, as a type of network agreement, does not only facilitate the sharing of knowledge but it increases the potential creation of new learning methods, which can be used for the benefit of the community as a whole and/or together with its members singularly. This approach is at the basis of the operation of a participated Network in which the mutual continuous exchange of information, experience, professionalism and performance represents the driving force of growth paths of the whole school system, personal development and rationalization in the use of public resources.

The contribution given by the school in favour of a smart, sustainable, inclusive growth, leads to reflect on the incompleteness of a model of accountability only focused on social dimension, given the close interrelationship between social function and ability of effective and efficient use of limited available financial 
resources. In this sense, the Social Accountability System represents the basis for the improvement of the cycle performance management of the schools (Figure 1). In particular:

- Combining autonomy and empowerment of schools, through the consolidation and strengthening of evaluation tools relevant to the autonomy tending toward a path of constant improvement of school governance, strengthening the mechanisms for planning and control and the constructive comparison with other realities of the system (Governance Sustainability).

- Increase the culture of evaluation within the school, retracing the measurement cycle and school management, enhancing the social communication addressed to all stakeholders to promote the stakeholder engagement and the inclusiveness (Network Governance).

- Promote the stakeholder engagement to improve the overall effectiveness of the School offer for the benefit of students, institutes and staff, institutions, families, communities and territory (Learning Communities).

Figure 1: The impact of Social Accountability System in the School Management

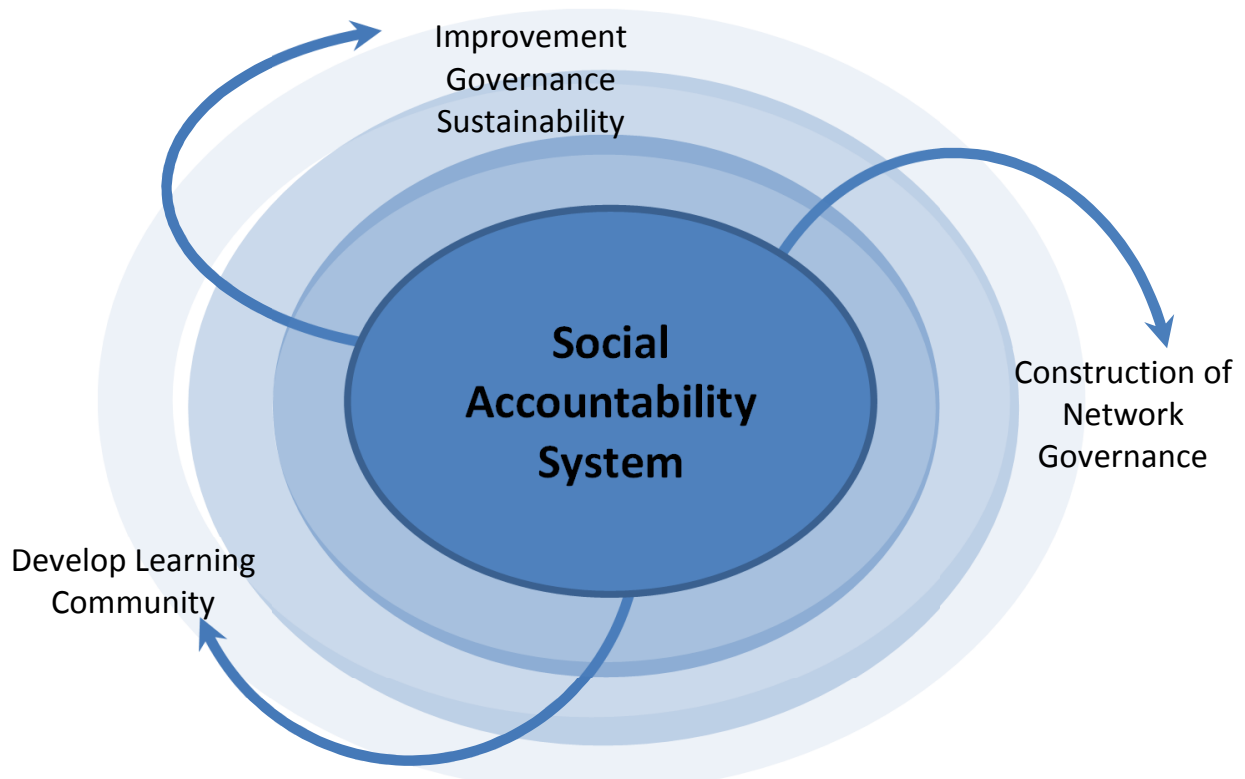

A social accountability system focused on the transparency and autonomy of the school governance should facilitate the overcoming of some difficulties and to fill the numerous gaps currently present in the Italian school system. In particular:

- To recover the transparency in the cycle Resources/Activity/Results of the administrations to allow the citizens to appraise its performances in comparison to the mission;

- To widen the measurement of the results, mostly limited to the accounting recognition according to nature and not also to the assessment of the destination and resource allocation with respect to the actions and their social effects; 
- To enhance the communication, in order to organize and to give significance to the information flow;

- To increase the legitimacy and confidence of the various social partners.

To this end, it becomes necessary to study and to propose to the operators of the sector new tools of accountability as the institutional communication current of the school system is insufficient and ineffective in terms of transparency and informative completeness and in terms of managerial and planning support.

\section{Conclusions}

Italian schools show a progressive sensibility increase for networks creation and reporting, both according to the need of improving the educational quality and the positive interaction with environment and according to the progressive attention of families and institutions towards the school system. In addition, schools are required to implement, in a relatively short time, the recent regulatory legislations, that considers as last step of the national evaluation system the activation of a process of social reporting.

The current networks, developed in Italy, in the educational field have evidenced an adequate success. According to INVALSI surveys, already in 2004, nearly 74\% schools declared to participate in school networks. In $38 \%$ of the cases, schools claimed to have been leaders of local network and in $20 \%$ of cases networks were made up of more than 20 school institutions.

However, it is important to underline that the efforts about social accountability, currently carried on in Italy, have derived from the personal interests of headmasters or from single institutions and they are limited to the development of a Sustainability Report. It is a representation, which is even directed to a wide audience of stakeholders but does not permit the full appreciation of relations between economic and socio-environmental responsibilities.

On the other hand, networks currently present in Italy, mostly associations or network agreements, aim at staff training (approximately $73 \%$ of cases, source INVALSI) and teaching planning (44\% of cases), while networks whose aim is the fulfilment of common activities among students (34\% of cases) are scarcely diffused and even less common is the realization of services shared by the network and complete systems for stakeholders' engagement.

According to what has been reported, the Italian case highlights an important gap: an organized and participated network of the school on social accountability system is missing while the knowledge and evaluative stakeholders' needs is increasing.

What stated above expresses the synthesis of data from a recent survey developed in the month of October 2017 by the University of Brescia. These are the first results of a biennial research aimed at identifying the best model of social accountability for the schools. The survey had to subject all the schools of every order and degree, of the province of Brescia, Lombardia, Italy (344 schools) which was subjected to fill out online evaluation questionnaire intended to highlight the perception of the impact of the national system of assessment on the part of the operators of the sector. First of all it is significant highlight the response rate. Were received 408 responses with a 
territorial coverage of response over $95 \%$. This means that for the same institute the questionnaire was completed by more than one subject (school manager and/or the Director of General Services Administration and/or a professor and/or employees). It emerges without any doubt a strong interest and attention to the theme from the schools.

The main emerging requirement is to understand and receive adequate training on the theme of reporting and evaluation. In particular, the National Evaluation System is very important to the management school in the $39,7 \%$ of cases. In the $26 \%$ of cases it is considers important but not necessary for the management. In the $27,2 \%$ of cases on thinks that the National Evaluation System is useful but not contextualized and in the 7,1\% of cases the schools think that it isn't useful for the schools but for other institutions. With specific regard to the Social Accountability, the survey show that in the $49,50 \%$ of cases the schools think that it isn't only a regulatory imposition, while in the $50,5 \%$ of cases it is. Nevertheless the $81,4 \%$ of cases think that the social accountability represents an opportunity to improve performance management and in the $68,4 \%$ of cases it represents an effective instruments of management control. Moreover the $70,1 \%$ of the schools considers the social accountability system a good way to build network.

Therefore, the information requirements on the subject of evaluation and reporting confirms the assumptions of this study, namely the need to align the managerial skills of school governance to changes in regulatory and context that are affecting the school management in these years and that, above all, intensified further in the direction of sustainable development initiated by Agenda 2030.

\section{Bibliography}

Aggarwal, R. (2000), Stabilization Activities by Underwriters after Initial Public Offerings, The Journal of Finance, LV(3).

Albareda, L. \& Waddock, S. (2016). Networked CSR Governance: A Whole Network Approach to Meta-Governance. Business \& Society, 1-40.

Boeve-De-Pauw, J., Gericke, N., Olsson, D. \& Berglund, T. (2015). The Effectiveness of Education for Sustainable Development. Sustainability, 7. https://doi.org/10.3390/su71115693

Bradely, S., Crounchely, R., Millington J. \& Taylor, J. (2000). Testing for quasi-markets Forces in secondary education. Oxford Bulletin of Economic and Statics, 62(3).

Brondoni, S. M. (2014). Global Capitalism and Sustainable Growth. From Global Products to Network Globalisation. Symphonya. Emerging Issues in Management, 1, 10-31. http://dx.doi.org/10.4468/2014.1.02brondoni

Brondoni, S.M. (2015). Global Networks, Outside-In Capabilities and Smart Innovation. Symphonya. Emerging Issues in Management, 1, 6-21. http://dx.doi.org/10.4468/2015.1.02brondoni

Burton, B. K. \& Dunn, C. P. (2005). The caring approach and social issues in management education. Journal of Management Education, 29(3). 
Cassano, R. \& Franzoni, S. (2010), Public procurement, CSR and sustainability: the present situation of Italian local public administrations, International Research Society for Public Management.

Cullen-Lester, K. L., Woehler, M. L. \& Willburn, P. (2016). Network-Based Leadership Development: A Guiding Framework and Resources for Management Educators. Journal of Management Education, 40(3), 321-358.

Exworthy, M., Powell, D., Mohan, J. (1999), Markets, bureaucracy t and public management: the NHS: quasi-market, quasi-hierarchy and quasi-network? Public Money and Management, 19(4).

Franzoni, S. \& Gennari, F. (2013). School Networks and Sustainable Development. Symphonya. Emerging Issues Management, 2, 32-46.

Gandini, G., Gennari, F. \& Cassano, R. (2014). Global Responsibility and Strategic Risk Management. Journal of Business Management Applied Economics, 3, 1-17.

Hastings M., Chapman C. (2009), Leading school-based Networks, Routledge, ISBN 9780415464659.

Hooijberg, R. \& Lane, N. (2009). Using multisource feedback coaching effectively in executive education. Academy of Management Learning and Education, 31.

Kerr, K. \& Dyson, A. (2016). Networked Social Enterprises: A New Model of Community Schooling for Disadvantaged Neighborhoods Facing Challenging Times. Educational Sciences, 6, 20 .

Le Grand (1991), Quasi-markets and Social Policy, Economic Journal, 101, 1256-1267.

Le Grand (2006), A Better Class of Choice, Public Finance.

Lozano, R. (2006). Incorporation and Institutionalization of SD into Universities: Breaking though Barriers to Change. Journal of Cleanear Production, 14, 787-796.

Mackintosh, M. (1992), Networks, Partnerships and Urban Regeneration, The Journal of the Local Economy Policy, Unit February, 1, 333-342.

Mitchell, R.K., van Buren, H.J., Greenwood, M. \& Freeman, R.E. (2015). Stakeholder Inclusion and Accounting for Stakeholders. Journal of Management Studies, 52, 851-877.

Salvioni, D. M., Astori, R. (2013). Sustainable Development and Global Responsibility in Corporate Governance. Symphonya. Emerging Issues Management, 1, 1-25. https://doi.org/10.4468/2013.1.03salvioni

Salvioni, D. M., Astori, R., \& Cassano, R. (2014). Corporate sustainability and ethical codes effectiveness, Journal of Modern Accounting and Auditing, 10(9), 969-982.

Salvioni, D. M. \& Cassano R. (2017). School Governance, Accountability and Performance Management. International Journal of financial Research, 8, 176-181, ISSN: 1923-4023. https://doi.org/10.5430/ijfr.v8n2p176

Salvioni, D. M. \& Cassano R. (2015). Improvement of management performance in the School System. In the $3^{\text {rd }}$ Virtual Multidisciplinary Conference, December 7-11/2015, www.quaesti.com, 3, 108-112, ISBN: 978-80-554-1170-5. https://doi.org/10.18638/quaesti.2015.3.1.202

Salvioni, D. M., Franzoni S. \& Cassano R. (2017). Sustainability in the Higher Education System: an Opportunity to Improve Quality and Image. Sustainability, 9, ISSN: 2071-1050.

Salvioni, D. M., Gandini, G., Franzoni, S. \& Gennari F. (2012). The role of key actors in school governance: an Italian evidence. US-China Education Review. B, Education Theory, 2, 881-897.

Stubbs, W. \& Cocklin, C. (2008).Teaching sustainability to business students: shifting mindsets. 
International Journal of Sustainability in Higher Education, 9(3), 206-221.

Tilbury, D. (2011). Higher Education for Sustainability: A Global Overview of Commitment and Progress. In Higher Education in the World 4; Higher Education's Commitment to Sustainability: From Understanding to Action; GUNI, Ed.; Palgrave: Barcelona, Spain, 1-21.

Tooley, J. \& Dixon, P. (2005), Private Education is Good for the Poor: a study of private schools serving the poor in low-income countries, Washington DC: Cato Institute.

Uitto, A. \& Saloranta, S. (2017). Subject Teachers as Educators for Sustainability: A Survey Study. Educational Sciences, 7(1), 8. https://doi.org/10.3390/educsci7010008.

West A. \& Pennel H. (2002), How New is New Labour? The Quasi-markets and English Schools 1997 to 2001, British Journal of Education Studies. 